\title{
Environment 2.0: Participatory Mass Observation
}

\author{
Editorial by Drew Hemment \\ Leonardo
}

At 8:30 PM on 28 March 2009, hundreds of millions of people living in the world's major cities were invited to turn off their lights for Earth Hour 2009. The world, then, may at last be waking up to the global crisis of climate change; this also testifies to the global connectedness possible with modern electronic media.

Environment 2.0 was initiated in 2006 to explore contributions to the sustainability of the way we live our lives. It involves participatory art and design projects that collaboratively produce and make sense of information about natural, built and social environments. We envision an exploration of how locative art can develop "new senses" and share discoveries with neighbors and people around the globe to become a part of a worldwide network of "one billion eyes."

Environment 2.o has taken me on a journey, comprising encounters with climatologists, climate hackers, DNA barcoders, urban gardeners, peak oil activists, butterfly enthusiasts and all points between. Staging events in Manchester, Singapore, Lancaster, Amsterdam and Berlin, I began in the role of curator and artist, and along the way found myself in discussions with the U.K.'s Ministry of Transport on how art methods can ignite innovation on sustainable transport, working as a weather forecaster with the Met Office in a series of mass participation projects, and adding an engagement with the environment to the FutureEverything festival's now-perennial themes of society, technology and the city.

In urban environments in particular, we are separated from the consequences of our actions as surely as the tarmac of the road cuts us off from the earth beneath. This physical boundary encourages a phenomenological separation. Innovative approaches to participatory observation and mapping can overcome this separation when combined with the way the Internet and digital media have enabled individuals to produce and share information globally and instantly. Cracks in the pavement can be widened by creative intervention or social innovation---artworks, social entrepreneurship, scientific intervention or innovations that harness everyday creativity.

Society's relationship with the environment is increasingly mediated by digital tools. Industrial societies have viewed the environment as a resource to be exploited and tamed. Now a new relationship to environment is beginning to emerge. Mapped, tagged and digitized, the world ceases to be inert raw material (or standing reserve) and becomes instead digitally navigable, computable, manipulable, understandable and experience-able in new ways.

Pervasive and locative arts enable people collectively to participate in sampling their lives, cities and environments, producing new datasets and visualizations in an active engagement with the mediated environment. These forms enable monitoring of digital traces in the environments: footprints in a navigable world. This makes possible an interface between our digital footprint, our environmental footprint, the resources we 
use and the burden we place on the environment.

Glocal, lobal connections are critical here. One of the Internet's most powerful impacts, in fact, is at a local level. Social technologies can be a catalyst for local social interactions; witness the success of schemes such as Freecycle and craigslist. These global technologies can also enable people to experience and monitor the changing climate and the effects of what they do, locally and globally.

Increasingly, people are routinely generating data about their environment simply by using media devices connected to the Internet. There are possibilities for environmental sensing that leverage social networks at a very large scale, and for community sensing involving social media and pervasive networks. Envisioning millions of users, each a broadcaster, presents challenges of the intelligibility of a million different data sources, as well as issues of accountability.

As the heat rises, more and more people are engaging with the environment and the challenge of climate change in creative and often unexpected ways. Environment 2.0 investigates the potential for participatory mass observation and builds in a capacity to collect, interpret and develop a critical mass of ideas, experiences and motivations into solutions that can transform our engagement in the environment.

Drew Hemment

Leonardo Guest Editor

Member, Leonardo Lovely Weather Working Group

Environment 2.O

$<$ http://labs.futureeverything.org/env2o > 